\title{
ROLE OF BIOGENIC WASTE AND RESIDUES AS AN IMPORTANT BUILDING BLOCK TOWARDS A SUCCESSFUL ENERGY TRANSITION AND FUTURE BIOECONOMY - RESULTS OF A SITE ANALYSIS
}

\author{
Andrea Schüch ${ }^{1, *}$, Jan Sprafke ${ }^{1}$ and Michael Nelles ${ }^{1,2}$ \\ ${ }^{1}$ University of Rostock, Faculty of Agricultural and Environmental Sciences, Department of Waste and Resource Management, 18059 \\ Rostock, Germany \\ ${ }^{2}$ Deutsches Biomasseforschungszentrum gGmbH, 04347 Leipzig, Germany
}

Article Info:
Received:
15 July 2019
Revised:
10 February 2020
Accepted:
12 February 2020
Available online:
5 March 2020
Keywords:
Biogenic waste and residues
Bioenergy
Energy transition
Net stability
Bioeconomy

\section{INTRODUCTION}

The world's population currently faces two fuel-related challenges: environmental degradation and resource scarcity. Environmental degradation includes global climate change, air toxicity, inadequate solid waste disposal, decreasing drinking water quality and the decline in insect populations. Every region of the world is affected but to different degrees. The global energy system is still dependent on fossil fuels and ranges from 32 to $100 \%$ in individual countries. Germany belongs to the group of countries with high fossil fuel dependency (>85\%) along with China, India, Japan, the U.S. and Russia (Ediger 2019, BP 2019, Ediger 2007).

The energy transition, which includes the transition into a low-carbon economy, will only be possible with the decarbonization of the energy system (Ediger 2019). Multiple approaches have to be combined to be successful: (1) energy savings through greater efficiency, (2) increasing the proportion of low-carbon-intensity fossil fuels such as gas, (3) increasing the proportion of renewables, and (4) carbon capture and storage technologies. The energy transition goes hand in hand with a transition of the fossil-based economy into a bioeconomy. The German renewable energy goals are ambitious, e.g. increasing the share of renewables to $65 \%$ by 2030 (related to the electricity supply, BMWi 2019).

Across the world and in Germany, In Germany, but also worldwide, renewable energies - especially wind and solar - have increased remarkably in recent decades. Globally, bioenergy is however still the most important renewable energy source. This may change in the future. Both worldwide and in Germany the bioenergy share, mainly from wood and energy crops, is around 7 to 9\% (FNR (2019): $7.1 \%$ of the German primary energy consumption (PEC) in 2018, IEA (2017): 9\% of global total primary energy supply in 2015). In the federal state of Mecklenburg-Western Po- 
merania, wind power has overtaken bioenergy (StatA MV 2017).

In contrast to the situation in many other countries, bioenergy in Germany is often based on energy crops. As a result of changing political frameworks, the bioenergy industry has to use alternative substrates such as biogenic waste and residues and to implement more efficient utilization pathways. But biogenic waste and residues are limited. At the same time, there is still unused potential - for example, one-third of the technical potential of waste biomass in Germany is still unused. By tapping the full potential, biogenic waste and residues could cover around 7 to $9 \%$ of the total PEC in Germany. Assuming decreased energy consumption, this share could increase to up to $15 \%$ (Brosowski et al. 2016).

The objective of sustainable integration of bioenergy into future global energy and bio-based economic system can only succeed if bioenergy is integrated as efficiently as possible, in a way that is environmentally sound and with the greatest possible economic benefits. Bioenergy, including that from biogenetic waste and residues, can contribute to this goal. Worldwide the demand for biomass will increase to meet the demand for material and energy (Piotrowski et al. 2015, Hoogwijk et al. 2005). The amount of biogenic waste and residues is also increasing. Seven billion people (in 2011) produce around 1.3 billion Mg dry matter (DM) organic waste per year and the world's population is still growing. Around one-third of this dry matter is food waste ( 0.51 billion Mg DM), since globally $30 \%$ of all food is wasted (Piotrowski et al. 2015, Schüch et al. 2017).

Globally and in Germany it seems to be clear that we have to explore the whole potential of biogenic waste and residues to cover our future needs. But to realize the available potential implementation at the local level is necessary. The advantages and limits of the available waste and residues for the energy transition and the bioeconomy are not well known at the federal state level. To determine the situation in Mecklenburg-Western Pomerania a site analysis was undertaken. The high biomass and renewable energy potential combined with low own energy demand from within the state make this area especially interesting. The aim of the study is to encourage developments that will make the state a pioneer in the field.

The objective of this study is to consider the role of biogenic waste and residues in the federal state of Mecklenburg-Western Pomerania for the energy transition and the bioeconomy. The paper will present selected results of site analysis and introduce technical solutions to how bioenergy plants could produce electricity (and heat) flexibly to stabilize local power grids and to contribute to the supply of renewable energy.

The objectives can be described as follows:

i. To describe the importance of bioenergy and biogenic waste and residues in a renewable energy system and bioeconomy.

ii. To compare the current status of bioenergy with the technical biomass fuel potential.

iii. To calculate the potential of biogas plants in the study area for sector coupling, with a focus on biogas up- grade and power-to-gas processes.

iv. To assess the possible contribution of biogenic waste and residues for the energy transition and the bioeconomy in the study area.

\section{MATERIAL AND METHODS}

The available literature, reports and statistical data are analyzed to answer the set objectives. The study area is the federal state of Mecklenburg-Western Pomerania. For the site study, data were found in annual abstracts of energy statistics (StatA MV 2018 and 2017, BNetzA, EM MV 2018), annual waste management reports (LUNG 2018), a bioenergy potential report (AEE 2013) and the results of external analysis and our own based on surveys (Daniel-Gromke et al. 2017, Orth and Schüch 2018). The data were analyzed by means of Exel. German trends and developments were projected to the federal state using an allocation mechanism and local data.

\subsection{Bioenergy in a renewable energy system}

Fossil and biomass power plants (and combined heat and power (CHP) units) need to be optimized regarding their flexibility parameters to be able to integrate as much fluctuating renewable energy as possible and in that way maintain the stability of the electrical grid. Ancillary services can be categorized as primary, secondary or tertiary frequency control reserves (Hübel et al. 2018).

A wide variety of proven and future options are available for bioenergy generation. Biomass in the form of liquid, solid or gaseous energy carriers can be converted in a way that can fulfill the requirements of the different power products within the markets. The ability to store biomass and its derived energy carriers is an almost unique advantage compared to other renewable sources (Szarka et al. 2013).

Bioenergy, including that from biogenic waste and residues (Nelles et al. 2015), can provide the positive and negative electrical capacity to avoid the retaining of fossil energy sources in a more and more renewable energy system (Holzhammer et al. 2015, Mauky et al. 2014). The increasing share of fluctuating renewable energies such as wind and solar power needs to be balanced in a way that substitutes the most harmful fossil fuels (Holzhammer et al. 2013). Already today advanced biogas plants are able to meet this flexibility demand. A pilot project has shown that demand-oriented energy production is also possible for solid biomass conversion plants (Hoffstede 2013). About $50 \%$ of German biomass plants are able to provide energy in a flexible way (Szarka et al. 2013).

Biogas plants cover today in Germany about $4 \%$ of the gross electricity consumption. These plants as a future flexibility option (installed capacity of 1,500 MW, which corresponds to one-third of the current capacity) can decrease the surplus generation of renewables by about 8 to $10 \%$ compared to the reference scenario in the same period. (Lauer and Trähn 2017, FNR 2018)

Biomass-based fuels have a significant advantage over other renewable heat sources. One benefit is that by burning solid biomass, combustion temperatures of up to $500^{\circ} \mathrm{C}$ are common and even temperatures above $1,000^{\circ} \mathrm{C}$ 
are possible when burning biomethane or hydrogen from power-to-gas processes.

The interactions between the provision, storage, conversion, transport and use of energy are very complex (Figure 1). The use of and demand for thermal energy is very strongly influenced by the economic sector in which it is used. Companies with relatively similar products have a different energy demand than companies with changing production. Furthermore, a distinction is made between low temperature $\left(<100^{\circ} \mathrm{C}\right)$, medium temperature $\left(100-500^{\circ} \mathrm{C}\right)$ and high temperature $\left(>500^{\circ} \mathrm{C}\right)$ levels. Exemplary technologies are cleaning, cooking, pasteurization, bleaching, drying, washing and pressing. The use of heat in industrial processes can furthermore contribute to sectoral coupling.

\subsection{Role of biogenic waste and residues in the bio- economy}

Biogenic waste and raw materials are to be used even more efficiently in the green or bioeconomy (Nelles 2017). Current research focuses on integrated biorefinery concepts and the production of basic chemicals, specialized fibres or fillers, and biocomposites or chars based on biodegradable waste (Schüch et al. 2017). The (new) combination of technologies can lead to new or better products or enhance energy efficiency. Ding et al. (2017) describe for example the pretreatment of food waste by hydrothermal carbonization followed by two-stage anaerobic digestion.

The aim of a biorefinery concept is to produce high-value bioproducts by means of valorization. Several research and demonstration projects have been implemented and reported (e.g. Schüch et al. 2016, Cimpan et al. 2015, Raussen and Wagner 2017, Aichinger et al. 2015).

In the future, energy-efficient biowaste treatment plants are not only intended to safely fulfill their disposal and recycling function, but also to supply the electricity in line with demand and to link sectors such as transport and heat in an optimal way (Figure 2). Besides these new develop-

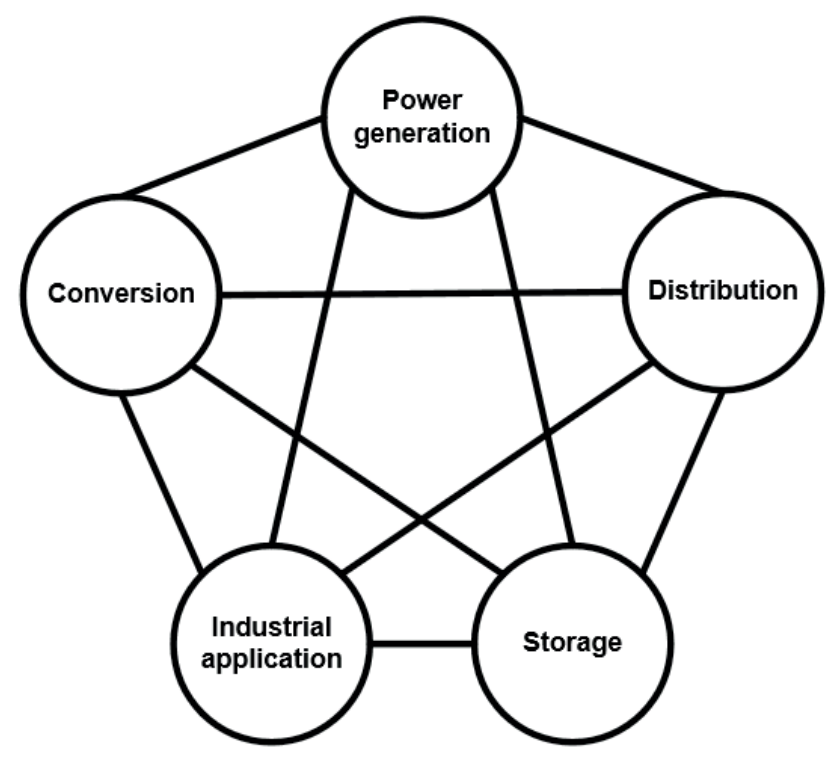

FIGURE 1: Interaction between provision, storage, conversion, transport and use of energy. ments, traditional and proven technologies retain their importance (Schüch et al. 2017).

\section{SITE ANALYSIS: FEDERAL STATE OF MECKLENBURG-WESTERN POMERANIA}

Mecklenburg-Western Pomerania is located in the north of Germany on the Baltic Sea, bordering on Poland. With an average of 69 people per $\mathrm{km}^{2}$ (45 in the countryside to 1,149 in the biggest city of the federal state), Mecklenburg-Western Pomerania is a low-populated state with migration from rural to urban areas (StatA MV 2018).

The demand centers for energy are strongly connected with population density and industry, in other words, and around the bigger cities as Rostock, Schwerin and Neubrandenburg and in coastal port towns. The federal-state is affected by demographic change, which influences living models, consumption and waste disposal structures.

Besides factors such as living standard, income and season, the site-specific creation of biowaste is connected to population density. Therefore the total potential of biowaste is low in the federal state. The separate collection of biowaste is not undertaken everywhere. In some regions, only green waste or garden waste is collected. In a nationwide comparison, the collected amount is relatively low. The annual German average amount of collected biowaste is $58 \mathrm{~kg}$ fresh mass (FM) per inhabitant (Kern et al. 2018) but in Mecklenburg-Western Pomerania only 29 $\mathrm{kg}$ (FM) (LUNG 2018). With the introduction of obligatory separate collection of biowaste nationwide the amount per capita increased slightly (e.g. from 2016 to 2017: +9.1\%, LUNG 2018). In addition to the biowaste, per inhabitant $52 \mathrm{~kg}$ (FM) green waste was collected in the federal state (LUNG 2018). The separately collected bio- and green waste amounted to $131,022 \mathrm{Mg}$ (FM) in 2017 (LUNG 2018). In comparison, the potential of agricultural residues and by-products especially for straw with around 1,070,600 Mg (TM), is much higher (AEE 2013).

The federal state has a technical biomass fuel potential of up to $31,000 \mathrm{GWh}$ (AEE 2013). This corresponds to about $8 \%$ of the German potential. The highest potential was found for energy crops and forest biomass with 16,528 and $7,056 \mathrm{GWh} /$ a respectively, followed by straw with 3,056 $\mathrm{GWh} / \mathrm{a}$ (AEE 2013). According to this reference, the technical fuel potential of organic waste and residues amounts to $8,750 \mathrm{GWh} / \mathrm{a}$. Therefore around $22 \%$ of the yearly energy consumption of the state could be covered by this source (in 2016 39,167 GWh energy was consumed, EM MV 2018).

\subsection{Renewable energy sector}

The geographic position of Mecklenburg-Western Pomerania makes the state especially suitable for wind power production. More than $60 \%$ (63.9\% in $2015,60.8 \%$ in 2016$)$ of the generated electricity are renewable energies, $25.2 \%$ and $26.8 \%$ respectively are from hard coal and around 10\% from fossil gases (EM MV 2018). Despite the adverse northern location with its relatively low solar radiation, in recent years the solar power sector has increased enormously (StatA MV 2017). The agrarian countryside with its high potential for biomass makes it especially suitable 


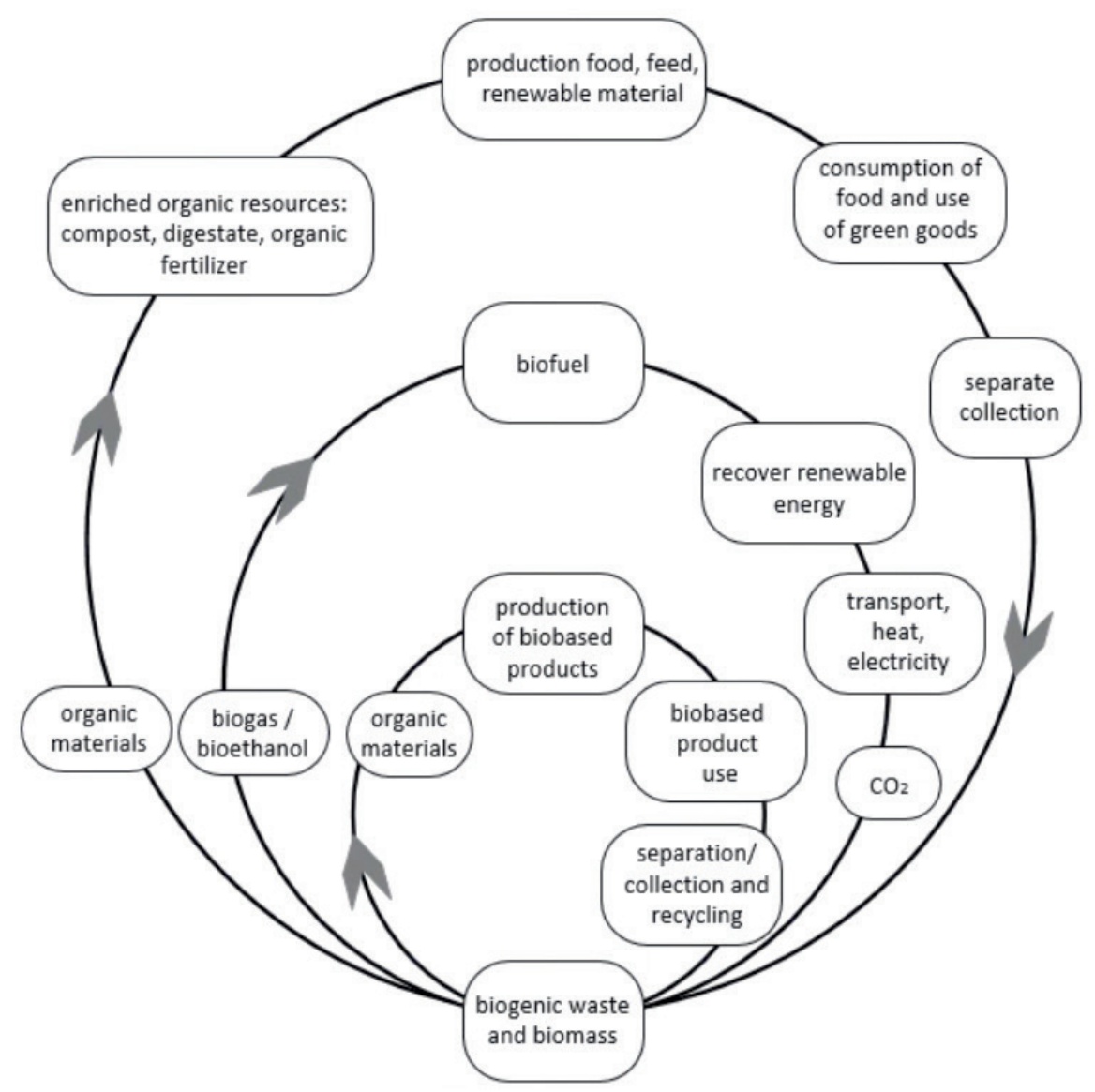

FIGURE 2: Biogenic waste and biomass in the circular economy (author's figure after ECN 2019, adapted).

for bioenergy. Figure 3 shows the proportion of installed renewable energy capacity and net electricity production. Biomass, including biogenic waste and residues, contributes $25 \%$ to the federal renewable electricity production. Most were generated by using biogas or biomethane in cogeneration (StatA MV 2017).

The biogas sector is well developed: 250 agricultural biogas plants produce 840 million $\mathrm{Nm}^{3}$ biogas per annum. 542 biogas and biomethane CHP units are in operation. The total installed electrical capacity of these CHPs is $300 \mathrm{MW}$. Additionally, 15 biogas plants upgrade biogas into biomethane with a capacity of 135 million $\mathrm{Nm}^{3} / \mathrm{a}$ (StatA MV 2018, Daniel-Gromke et al. 2017). One biogas plant produces biogas from separately collected biowaste and uses this in cogeneration (capacity $18,000 \mathrm{Mg} / \mathrm{a}$, Remondis 2019); one other uses the mechanically separated organic fraction from mixed municipal solid waste (OFMSW and organic waste, capacity 40,000 Mg/a, Veolia 2019) and produces upgraded biogas. Besides this, a number of biogas plants use organic waste and residues from food production, agriculture, canteens and so on. Three of these upgrade the biogas into biomethane.

The electrical capacity of the plants that use solid and liquid biomass is $88 \mathrm{MW}_{\text {el }}$ (StatA MV 2017). Used biomass is mainly wood, waste wood and some plant oil. Biomass heat plants also use straw or dried grass from wetlands. Smaller thermal installations for biomass use, for instance, wood pellets or firewood.
In contrast, the installed electrical capacity of wind and photovoltaics is 3,310 and $1,426 \mathrm{MW}$ respectively, which together is $72 \%$ of the total renewable capacity (StatA MV 2017).

The availability of the bioenergy plants is high: with a share of $8 \%$ of electrical capacity, $25 \%$ of the renewable net electricity was provided in 2016 (StatA MV 2017, Figure 3).

Total electricity consumption in Mecklenburg-Western Pomerania is around $6,800 \mathrm{GWh}$ per year. In the state, more electricity is produced than consumed when considering the yearly balance. This means that the federal state exports electricity to other German regions or abroad. But this is not possible when the electrical network cannot transport electricity to demand centers as a result of network bottlenecks or low demand. Currently, this surplus energy is avoided by feed-in management measures (for electricity feed into the electrical grid) - producing plants are shut down for a time. This causes costs and valuable potential is lost. In the federal state the amount of loss was 317,570 MWh electricity in 2016 (StatA MV 2018). Figure 4 shows the distribution of renewable energy plants such as wind power and biogas plants as well as the location of electrical substations where the feed-in management measures took place.

The shut-down or curbed renewable energy plants are paid for the not produced electricity, which resulted in costs of $€ 29,9$ million in the year 2016 in the federal state ( $€ 372,7$ million in Germany, BNetzA 2017). Germany wide, $93.5 \%$ 


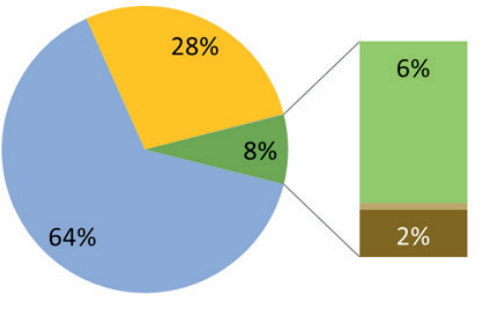

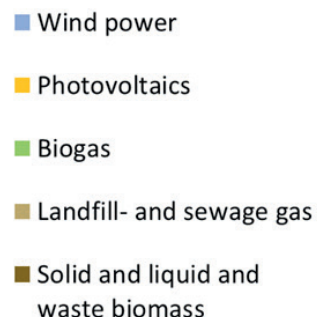

waste biomass

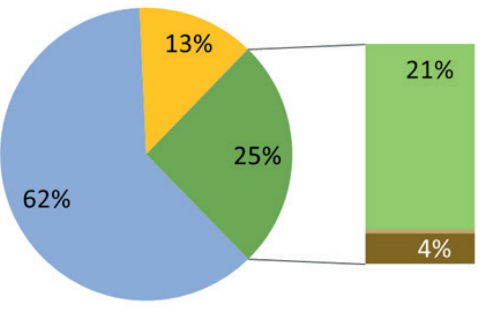

In total 4,922 $\mathrm{MW}_{\mathrm{e}}$, Datasource: Statistisches Amt Mecklenburg-Vorpommern 2017

In total 9,736,507 $\mathrm{MWh}_{\mathrm{e}}$, Datasource: Statistisches Amt Mecklenburg-Vorpommern 2017

FIGURE 3: The proportion of renewable energy in the German federal state of Mecklenburg-Western Pomerania. Right: installed electrical capacity, left: net electricity production in 2016 (Source: StatA MV 2017).

of these costs could be attributed to wind power plants in 2016. Since the wind energy sector is growing faster than the net revision, this will cause problems in the future, especially in Mecklenburg-Western Pomerania. The energy transition can only be successful if resources are used as efficiently as possible. One solution to use surplus energy is sector coupling. The electricity could be used to produce hydrogen by electrolysis and used for transportation, industry or as energy storage. It is also possible to produce methane from the hydrogen. For this conversion, $\mathrm{CO}_{2}$ is needed, which could easily be provided by bioenergy plants including waste treatment facilities. Biogas plants together with landfills and sewage sludge digestion plants in Mecklenburg-Western Pomerania could provide between 179 and 535 million $\mathrm{m}^{3} \mathrm{CO}_{2}$ per year (Orth and Schüch 2018). Additionally, biomass heat (and power) plants produce biogenic $\mathrm{CO}_{2}$. Biomethane plants which separate the $\mathrm{CO}_{2}$ from biogas can do this today already. For all these plants in the federal state, the capability of these $\mathrm{CO}_{2}$ sources is estimated at 50 to 65 million $\mathrm{m}^{3} / \mathrm{a}$.

\subsection{Electricity feed-in}

Not only is the amount of electricity supplied important for the site analysis, but also at which grid level it is fed. A distinction is made between high-voltage grids, high-voltage/medium-voltage grids, medium-voltage grids, medium-voltage/low-voltage grids and low-voltage grids. In Mecklenburg-Western Pomerania, biomass plants mainly feed into the medium-voltage grid, whereas plants with an installed (CHP) capacity of less than $100 \mathrm{~kW}_{\mathrm{el}}$ tend to feed into the low-voltage grid. Wind turbines, on the other hand, tend to feed their electricity at the medium and highest voltage levels. At the medium-voltage level, biomass, wind and solar plants feed-in electricity. Solar systems dominate the low-voltage level, at which few biomass plants and almost no wind turbines feed electricity (BNetzA 2017).

Important for future planning is also the spatial distribution of the plants. An accumulation of biogas and wind power plants can be found in the eastern part of the federal state as well as south of Rostock (Figure 4, Orth and Schüch 2018).
A calculation of the biogenic waste and residue share of the renewable electricity supply is difficult since statistical data are lacking and it was not possible to collect all information directly at the plants. But estimations could be made. Around $4 \%$ of the generated electricity comes from landfill, sewage gas CHP and liquid biofuels, and 21\% from biogas and biomethane CHP units (based on StatA MV 2018). The majority of the biogas is produced in biogas plants using $76.7 \%$ (energy-related) energy crops and $23.3 \%$ biogenic residues such as animal feces, municipal bio- and green waste and residues from industry and agriculture. The number of waste digestion plants is low: in the study area, six of more than 250 biogas plants are waste digestion plants. The installed capacity ranges from 370 up to $2,000 \mathrm{~kW}_{\mathrm{el}}$. For biomethane $82 \%$ (energy-related) energy crops are used and only $18 \%$ biogenic residues or waste (Daniel-Gromke et al. 2017). Based on this information and the statistical data on generated renewable electricity in 2016 (StatA MV 2018), the proportion of biogenic waste and residues of renewable electricity generation in the study area is estimated at $5.1 \%$, of biobased electricity generation at nearly $20 \%$, of total electricity generation at $3.4 \%$ and of total electricity consumption at $7.3 \%$.

\subsubsection{Flexibility of biogas plant CHPs}

Biogas plants, including waste digestion plants, are encouraged to generate energy in a demand-oriented manner. Different concepts are used, for example, the storage of biogas and CHP generation in times with higher market prices and low wind and solar power on the grid. This requires higher gas storage capacity and more CHP units (Schüch et al. 2017). One possibility to decrease the gas storage demand is flexible biogas production by means of adapted feeding strategies or the storage and selective supply of intermediates (Szarka et al. 2013). Biogas plants with on-site cogeneration or biomethane CHPs are able to offer ancillary services by operating reserves.

CHPs with biogas storage for several hours of operation is particularly suitable for securing the residual load for the daily compensation of fluctuating generation and consumption. For this purpose, the production is increased during peak load hours and the plant is operated according 


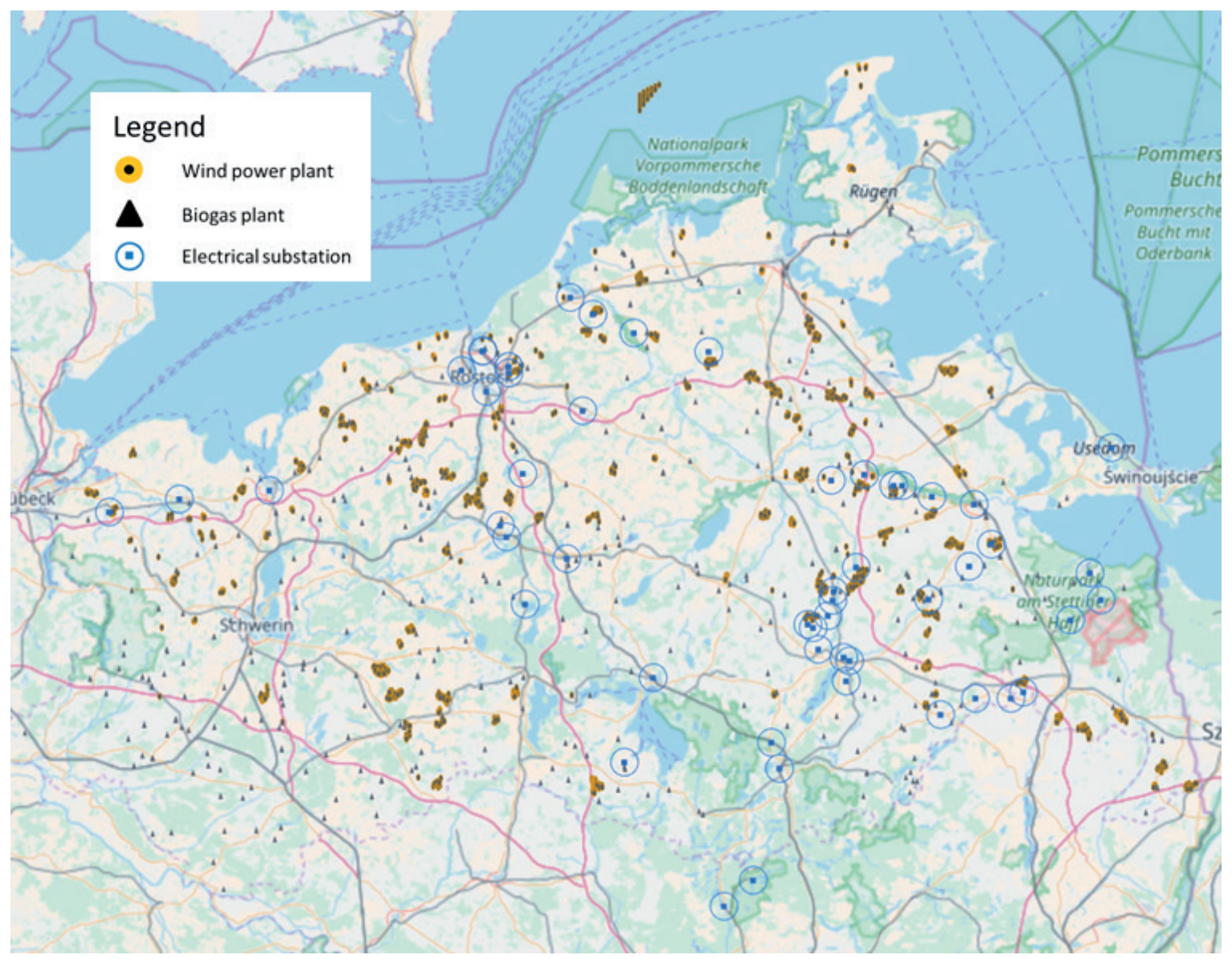

FIGURE 4: Distribution of wind power, biogas plants and electrical substations with feed-in management measures in Mecklenburg-Western Pomerania in 2016 (Orth and Schüch 2018 based on OpenStreetMap).

to a timetable that is based on the prices on the spot market (FNR 2018).

To estimate the degree of flexibility for a demand-based power supply in the federal state of Mecklenburg-Western Pomerania, the ratio of installing to rated power and the presence of several CHPs are important. This however could not be determined in the project due to incomplete data. The use of the flexibility bonus (flex bonus, a special additional feed-in tariff of the German Renewable Energy Sources Act (EEG)) can be used as an indication of the possibility of flexible CHP operation. Through this bonus, the investment in additional CHP capacity can be partially refinanced. Experts assume that participation in the tendering model (replacing the former EEG tariffs) is hardly economically feasible without the use of the flexibility bonus. The main reason for this is that the EEG remuneration is lower and, at the same time, the financial burden of the necessary investments is higher (higher CHP capacity, storage, and repair of the stock). The use of the flexibility bonus is limited and has been reduced from 1,350 to 1,100 $\mathrm{MW}_{\mathrm{el}}$ installed capacity (Neumann 2018). In May 2017, the flex bonus had been used for $355.4 \mathrm{MW}_{\mathrm{el}}$ nationwide, and as of December 2018 for $900.5 \mathrm{MW}_{\mathrm{el}}$ (BNetzA register of facilities, as of $05 / 2017$ and as of $12 / 2018$ ). It was assumed that the flex bonus fee will be exhausted by summer 2019 (Neumann 2018).
Based on the installed capacity of biogas plants in Mecklenburg-Western Pomerania $\left(268 \mathrm{MW}_{\mathrm{e}}\right)$, the flex bonus was used for about $30 \%\left(78 \mathrm{MW}_{\mathrm{el}}\right)$, whereby 49 biogas plants did not increase their capacity and 34 plants did increase their capacity (BNetzA, in the period from 08/2014 until the end of $12 / 2018$ ). However, a statement on the rate of flexibilization cannot be drawn as the design performance of the biogas plants has not been published. Based on the data, however, it can be assumed that $30 \%$ of the biogas plant capacity or around 156 biogas plants can be operated flexibly (with on-site electricity generation, on the basis of an average of $500 \mathrm{~kW}_{\mathrm{el}}$ per plant).

The investigation of flexible operation of waste digestion plants is part of the Netz-Stabil project and is still in progress. Initial results show that flexibility options are available, but legislation and technical and economic barriers currently exist (Sprafke et al. 2019).

\subsubsection{Flexibility of biomass power plants}

Besides the production of heat and electrical energy, thermal power plants supply system stability to the electrical grid by providing ancillary services.Currently installed wind and photovoltaic generators are not able to supply primary control reserves. Alternative technologies such as large batteries are not yet available on the required scale. Studies by Hübel et al. (2018) show that flexibility improve- 
ments at a reference hard coal power plant led to significant economic benefits compared to similar changes at a gas turbine power plant. In addition, specific improvements in cash flow can be calculated when future market price functions are used.

Biomass heat and power plants are working with similar technical principles, but usually at a lower scale than hard coal power plants. An important difference is that these plants are designed to supply a consumer (industry, district heat, etc.) with heat, which means they are driven by heat demand. Combined with heat storage and smart management of internal storage options these plants could provide electricity in a more flexible way than today, as confirmed in a pilot study by Hoffstede (2013).

\subsection{Heat sector}

\subsubsection{Heat from biogas CHP units}

By far the largest number of biogas plantsin Mecklenburg-Western Pomerania uses the generated biogas onsite in cogeneration. Demand-oriented biogas production and electricity generation is predominantly not implemented. In many plants, the generated heat is not fully utilized. This may because appropriate heat sinks are lacking or the demand does not match the availability of the heat. The heat demand of the biogas plants is highest in winter, while the heat surplus is usually highest in the summer. Since households have the lowest heat demand in summer, the available heat can usually not be fully used when a district heat network is only fed by a biogas plant CHP.

In order to estimate the current heat utilization of biogas plants in the federal state, the heat production was calculated from the net electricity production. Average system data were used for this, according to an electrical efficiency of 28 to $47 \%$ and a thermal efficiency of 34 to $55 \%$ (KTBL 2013). After deducting the amount necessary to supply the fermenter heating, this results in the available heat from biogas plant cogeneration units in Mecklenburg-Western Pomerania amounting to approx. 1.5 million $\mathrm{MWh}_{\text {th }}$ per year (Table 1). The net heat generation by power plants (owned by power utilities, industrial power plants and heating plants to supply $>500$ residential units) amounts to 3.9 million $\mathrm{MWh}_{\text {th }}$ (2016), of which 2.5 million MWh is generated from natural gas (Stat. MV 2017). The available heat from biogas CHPs, therefore, corresponds to approximately $38 \%$ of the net heat production.

In Germany, $90 \%$ of the biogas plants use the available heat externally (Daniel-Gromke et al. 2017). If this were used to cover heat sinks, in Mecklenburg-Western Pomerania surplus heat from biogas CHPs could thus replace $35 \%$

TABLE 1: Assumptions for estimating the potential for external heat use from biogas, landfill and sewage gas CHP units in the federal state of Mecklenburg-Western Pomerania.

\begin{tabular}{l|c|c} 
Plant type & $\begin{array}{c}\text { Plants heat demand of the } \\
\text { produced heat (KTBL 2013) } \\
\text { [\%] }\end{array}$ & $\begin{array}{c}\text { Available heat } \\
\text { for external use } \\
\text { [MWh }]\end{array}$ \\
\hline Biogas & 28 & $1,502,266$ \\
\hline Landfill gas & No demand & 32,308 \\
\hline Sewage gas & 28 & 11,631 \\
\hline
\end{tabular}

of the net heat generation (1.35 million $\mathrm{MWh}_{\mathrm{th}} / \mathrm{a}$ ). Currently, only $30 \%$ of biogas plants in Germany supply heating grids (Daniel-Gromke et al. 2017). Projected onto the federal state this would amount to about 0.33 million $\mathrm{MWh}_{\text {th }}$ or about $8 \%$ of the net heat generation.

Electricity is also generated via CHP technology by using landfill and sewage gas, and heat can also be available here. Although landfills do not have their own heat demand, they are mostly far from heat sinks, which make it difficult to use. Due to the decrease in landfill gas and methane concentration (since 2005, no untreated waste may be deposited), the amount of electricity and heat is declining. Wastewater treatment plants often use the waste heat from electricity generation to cover various requirements of the plant, but also to supply district heating networks (e.g. WWT Grevesmühlen).

\subsubsection{Heat from biomass plants}

In the heat sector, the share of renewables is around $20 \%$, which is dominated by biomass (Orth and Schüch 2018). The potential of biomass residues and waste from municipals, industry, agriculture and forest is high. Especially straw, stalky biomass from wetland or landscape cultivation as well as manure from animal husbandry is not fully used. Woody biomass is in competition with the wood industry, but at the same time, large wood processing plants are using their own wood residues for heat provision (e.g. Holzcluster Wismar). Examples of the efficient use of waste wood also exist. For example, the heat and power plant in Hagenow (Biotherm Hagenow $\mathrm{GmbH}$ ) provides all available heat for and district heat grid in an industrial site and recovers heat from the exhaust gas to dry (natural) wood chips to produce high-quality fuels with defined parameters (lower heating value, ash content).

\subsubsection{Biogas upgrade capacity and Power-to-Gas processes}

One option is to decouple the biogas production and upgrade the biogas into biomethane. In Germany, this could be stored and transported easily via the natural gas grid. Furthermore, biomethane can replace natural gas in high-calorific industrial processes.

Limiting factors are the availability of the natural gas grid and the economic feasibility for small plants $(<500 \mathrm{~kW}$ electrical equivalent capacity). So far this approach has only been economical for larger plants. In addition, a suitable natural gas pipeline must be available on-site. Research and development are being done to find applicable upgrade solutions with high efficiency, e.g. by using membranes (Park et al. 2017, Miltner et al. 2017).

The biogas upgrading capacity in Mecklenburg-Western Pomerania is currently 135 million Nm³/a (Daniel-Gromke et al. 2017). Three of the six waste digestion plants and additionally 15 agricultural biogas plants upgrade biogas into biomethane (Daniel-Gromke et al. 2017). According to Scholwin et al. (2015), approximately $10 \%$ of the installed capacity of biogas plants in Germany (with a minimum CHP capacity of $800 \mathrm{~kW}_{\mathrm{e}}$ ) is suitable for a biogas upgrade: if more than $50 \%$ of the heat produced in cogeneration cannot be utilized and marketed, biogas upgrade under certain conditions is an economical alternative. Projected onto 
the federal state, a capacity of about $26.8 \mathrm{MW}_{\text {el }}$ could be suitable for biogas upgrading (without biomethane CHP). Taking an average installed capacity of $500 \mathrm{~kW}_{\mathrm{el}}$ as a basis, this means that around 53 biogas plants may be suitable for biogas upgrade. In addition, there is still potential in the pooling of biogas plants that are not much further apart than $2 \mathrm{~km}$. The analysis, to identify the potential in the federal state for that solution is not finished yet.

As stated in section 3.2, separated $\mathrm{CO}_{2}$ can serve as a biogenic source for power-to-gas solutions. The total annual $\mathrm{CO}_{2}$ potential of the biogas (including waste digestion plants), landfill and sewage gas plants in Mecklenburg-Western Pomerania is at least 390 million $\mathrm{m}^{3} \mathrm{CO}_{2}$ and together with the biomethane plants around 440 million $\mathrm{m}^{3}$ $\mathrm{CO}_{2}$ (calculated from net electricity production, the reference year 2016, StatA MV 2017). With this amount of $\mathrm{CO}_{2}$ it would be possible to provide approximately 153 to 456 million $\mathrm{m}^{3}$ methane (methanation rate $85 \%$ ). To produce hydrogen approximately 6.3 million to 7.1 million $\mathrm{MWh}_{\mathrm{el}}$ is needed. This means that the whole loss by feed-in management measures $\left(317,570 \mathrm{MWh}_{\mathrm{el}}\right.$ in 2016) could be transferred into methane by biological or catalytic methanation.

\subsection{Bioeconomy}

Alongside the renewable energy industry and the health sector, agriculture is one of the most important economic sectors in the federal state of Mecklenburg-Western Pomerania. The percentage of agricultural areas is higher than the average in Germany (AEE 2013). The technical potential of residues from agriculture is high, especially of straw (technical potential 11,000 TJ/a) and manure from animal farming (technical potential 3,900 TJ/a) (AEE 2013). Besides the agriculture food processing industries as well as biofuel producing facilities are in operation and important employers locally. There is not much of a biobased industry, except the wood processing cluster in Wismar (Schüch et al. 2017). New pilot facilities have been established in the state such as Continental, which develops biobased tires (Holzhammer 2018). Altogether the potential to expand the bioeconomy in the federal state is high since a lot of space, biomass and renewable energy are available.

\section{CONCLUSIONS}

The energy transition goes hand in hand with a transition of the fossil-based economy into a bioeconomy. In the future, the circular economy will be strongly connected with the bioeconomy. The road to this "green economy" is a long one, but it is gaining more and more important in politics, industry and research. To make the transition from traditional waste disposal to circular and green economy happen, awareness and the willingness of the population to support this development through a good waste separation is essential. Besides technology, economy and ecology, social aspects also need to be considered.

Waste segregation is a key requirement for high-quality recycling products. These more valuable products could contribute to economically feasible management concepts. Biodegradable waste can be a valuable resource for energy generation and recycling. In many countries, its separate collection and high-quality utilization have been recognized as an opportunity for added value.

Mecklenburg-Western Pomerania has the potential to be an exporter of renewable energy, food, and biomaterial since the potential for generation is high. The technical fuel potential of biogenic waste and residues is lower than the total energy consumption but in the range of the electricity consumption of the study area. The currently achieved 493,658 MWh generated electricity from biogenic waste and residues represents only $5.6 \%$ of the technical fuel potential of organic waste and residues (8,750 GWh/a). Even when the cogenerated heat is considered, the scope for further exploitation is remarkable.

The main bioenergy plant stock consists of biogas plants that present a low flexibility rate. Only $30 \%$ of the installed electrical capacity uses a flex bonus. It is unlikely that plant operators are able to invest in additional CHP units to act in a more demand-oriented way. Therefore under the current framework, higher flexibility of the bioenergy plant stock cannot be expected. But activities of individual plant operators to improve the whole plant performance by installing additional CHPs and gas storage as well as improving the use of cogenerated heat in the study area are known by the authors. Since not many additional bioenergy plants are expected in the coming years, increasing installed capacity could be considered as growing the flexibility of the plant stock.

In the study area a number of biogas plants that use waste and residues as feedstock upgrade biogas into biomethane. This offers demand-oriented use in electricity, heat, mobility and industry sectors. Through the pooling of biogas plants, this option could be further developed for around $20 \%$ of the plants. Currently, surplus electricity is avoided by means of feed-in management. Producing plants are shut down, resulting in very high costs. Bioenergy plants generate climate-neutral $\mathrm{CO}_{2}$, which is needed in the future, e.g. for synthetic fuels or methanation. The potential of green $\mathrm{CO}_{2}$ in the study area is high. The current surplus electricity from wind energy plants could be transferred into biomethane by the $\mathrm{CO}_{2}$ of around 25 biogas plants (Orth and Schüch 2018).

The energy transition is only possible when the whole potential of wind, solar and bioenergy is explored. Further implementation means the installation of more renewable energy plants than are present today. This is an economic opportunity (jobs, regional added value) but also a challenge (exploitation of difficult waste substrates, logistics, infrastructure, and experienced personnel) and risk regarding nature protection (local nutrient surplus, emissions etc.). Altogether the energy transition and bioeconomy offer more opportunities than risks for the study area, but support from policymakers and a stable economic framework are needed to move forward with this development.

\section{REFERENCES}

AEE, 2013. Potenzialatlas Bioenergie in den Bundesländern. https:// mediathek.fnr.de/media/downloadable/files/samples/a/e/ aee_potenzialatlas_090114_2013_fnr.pdf, last website visit on 23.05.2019. 
Aichinger, P.; Kuprian, M.; Probst, M.; Insam, H.; Ebner, C., 2015: Demand-driven energy supply from stored biowaste for biomethanisation. Bioresour. Technol. 194, 389-393.,https://doi. org/10.1016/j.biortech.2015.06.147

BMWi 2019. Erneuerbare Energien in Zahlen - Nationale und internationale Entwicklung im Jahr 2018, Hrsg. Bundesministerium für Wirtschaft und Energie (BMWi), as of October 2019, https://www. erneuerbare-energien.de/EE/Redaktion/DE/Downloads/Berichte/ erneuerbare-energien-in-zahlen-2018.pdf?_blob=publicationFile\&v=3, last website visit on 27.11.2019.

BNetzA, 2017. Bundesnetzagentur: Quartalsbericht zu Netz- und Systemsicherheitsmaßnahmen Viertes Quartal und Gesamtjahr 2016.

BP, 2019. BP Statistical Review of World Energy 2019. https://www. bp.com/content/dam/bp/business-sites/en/global/corporate/ pdfs/energy-economics/statistical-review/bp-stats-review-2019full-report.pdf, last website visit on 15.11.2019.

Brosowski, A.; Thrän, D.; Mantau, U.; Mahro, B.; Erdmann, G.; Adler, P.; Stinner, W.; Reinhold, G.; Hering, T.; Blanke, C., 2016. A review of biomass potential and current utilisation - Status quo for 93 biogenic wastes and residues in Germany. Biomass and Bioenergy 95, 257-272. https://doi.org/10.1016/j.biombioe.2016.10.017

Cimpan, C.; Rothmann, M.; Hamelin, L.; Wenzel, H., 2015. Towards increased recycling of household waste: Documenting cascading effects and material efficiency of commingled recyclables and biowaste collection. Journal of Environmental Management 157, 69-83. DOI: 10.1016/j.jenvman.2015.04.008

Daniel-Gromke, J.; Rensberg, N.; Denysenko, V.; Trommler, M.; Reinholz, T.; Völler, K.; Beil, M.; Beyrich, W., 2017. Anlagenbestand Biogas und Biomethan - Biogaserzeugung und -nutzung in Deutschland. Studie im Auftrag des Umweltbundesamtes, DBFZ Report Nr. 30 ISBN 978-3-946629-24-5.

Ding, L.; Cheng, J.; Qiao, D.; Yue, L.; Li, Y.; Zhou, J.; Cen, K., 2017. Investigating hydrothermal pretreatment of food waste for twostage fermentative hydrogen and methane co-production. Bioresource technology 241, 491-499. https://doi.org/10.1016/j. biortech.2017.05.114

ECN, 2019. Biowaste in the Circular Economy. EUROPEAN COMPOST NETWORK, https://www.compostnetwork.info/policy/circular-economy/, last website visit on 23.05.2019.

Ediger, V.Ş.; Hoşgör, E.; Sürmeli, A.N.; Tatıdil, H. 2007. Fossil Fuel Sustainability Index: An application of resource management. Energy Policy 2007; 35(5), 2969-2977

Ediger, V. Ş., 2019. An integrated review and analysis of multi-energy transition from fossil fuels to renewables. Energy Procedia 156, 2-6. https://doi.org/10.1016/j.egypro.2018.11.073

EM MV, 2018. Energie- und CO-Bericht 2017 - 2018 mit Energiebilanz und Bilanz energiebedingter $\mathrm{CO}_{2}$-Emissionen 2015 und 2016, Ministerium für Energie, Infrastruktur und Digitalisierung Mecklenburg-Vorpommern (Hrsg.), https://www.regierung-mv.de/ Landesregierung/em/Service/Publikationen/?id=18721\&processor=veroeff, last download 23.05.2019.

FNR, 2019. BASISDATEN BIOENERGIE DEUTSCHLAND 2018, Fachagentur Nachwachsende Rohstoffe e.V. (FNR), http://www. fnr.de/fileadmin/allgemein/pdf/broschueren/Broschuere_Basisdaten_Bioenergie_2018_web.pdf, last website visit on 15.11.2019.

FNR, 2018. Flexibilisierung von Biogasanlagen. Fachagentur Nachwachsende Rohstoffe e. V. (Hrsg.), https://fnr.de/fileadmin/ allgemein/pdf/broschueren/Broschuere_Flexibilisierung_Biogas_ Web.pdf, last download 23.05.2019.

Hoffstede, U., 2013. FlexHKW Flexibilisierung des Betriebes von Heizkraftwerken. In: Konferenzreader 5. Statuskonferenz "Energetische Biomassenutzung", 14./15. November 2013 in Leipzig. Leipzig: DBFZ, 2013, pp. 496499

Holzhammer, A., 2018. Russischer Löwenzahn als Lieferant für Naturkautschuk. Agrarheute 27.12.2018, https://www.agrarheute.com/ technik/traktoren/reifen-continental-loewenzahn-550458, last website visit on 19.11.2019.

Holzhammer, U.; Nelles, M.; Scholwin, F., 2013. Auswirkungen der flexiblen Stromproduktion aus Biogas auf den konventionellen Kraftwerkspark und dessen $\mathrm{CO}_{2}$-Emissionen, In: Kern, M.; Raussen, T. (Hrsg.): Optimierte Erfassung und Verwertung von Bioabfall, Reihe Witzenhausen-Institut, Neues aus Forschung und Praxis, S. 145167, Dezember 2013, ISBN 3-928673-65-3.

Holzhammer, U.; Stelzer, M.; Nelles, M., Scholwin, F., 2015. Die neue Flexibilität der Stromwirtschaft und die zukünftige Rolle der Abfallwirtschaft, In: Erich-Schmidt-Verlag (Hrsg.): Müll und Abfall, 02.15, S. 79-89, ISBN 978-3-503-12493-0
Hoogwijk, M.; Faaij, A.; Eickhout, B.; Vries, B. de; Turkenburg, W., 2005. Potential of biomass energy out to 2100 , for four IPCC SRES landuse scenarios. Biomass and Bioenergy 29, 225-257.

Hübel, M.; Prause, J.; Gierow, C.; Holtz, D.; Wittenburg, R.; Hassel, E., 2018. Evaluation of Flexibility Optimization for Thermal Power Plants, ASME Power and Energy Conversion Conference, 2018, Orlando, USA.

IEA, 2017. Technology Roadmap - Delivering Sustainable Bioenergy.

Kern, M.; Siepenkothen, H.-J.; Turk, T. 2018. Erfassung und Qualität von haushaltstämmigen Bioabfällen. 12. Biomasseforum "Neue Perspektiven für die Bioabfallwirtschaft", ISBN 3-928673-77-7, 53-68.

Lauer and Trähn, D., 2017. Biogas plants and surplus generation: Cost driver or reducer in the future German electricity system? Energy Policy 109, 324-336. http://dx.doi.org/10.1016/j.enpol.2017.07.016

LUNG, 2018. Daten zur Abfallwirtschaft. Landesamt für Umwelt, Naturschutz und Geologie Mecklenburg-Vorpommern (Hrsg.). https:// www.lung.mv-regierung.de/dateien/dza_2017.pdf, last website visit on 23.05.2019.

Mauky, E.; Jacobi, H.F.; Liebetrau, J.; Nelles, M., 2014. Flexible biogas production for demand-driven energy supply - Feeding strategies and types of substrates. Bioresour. Technol. 178, 262-269, https:// doi.org/10.1016/j.biortech.2014.08.123

Miltner, M.; Makaruk, A.; Harasek, M., 2017. Review on available biogas upgrading technologies and innovations towards advanced solutions. Journal of Cleaner Production 161, 1329-1337. DOI: 10.1016/j.jclepro.2017.06.045

Raussen, T.; Wagner, J.: EEG 2017 in der abfallwirtschaftlichen Prax is - Chancen für Bio- und EEG 2017 in der abfallwirtschaftlichen Praxis - Chancen für Bio- und Grüngutverwertungsanlagen. Müll und Abfall 7-2017, 328-334. https://www.muellundabfall.de/ MA.07.2017.328

Remondis, 2019. SAS gewinnt klimafreundlichen Strom aus Bioabfällen,https://www.remondis-aktuell.de/012015/recycling/mit-energie-fuer-schwerin/, last website visit on 23.05.2019.

Schüch, A.; Morscheck, G.; Lemke, A.; Nelles, M., 2016. Bio-waste Recycling in Germany - Further Challenges. Procedia Environmental Sciences 35, 308-318. https://doi.org/10.1016/j. proenv.2016.07.011

Schüch, A.; Morscheck, G.; Nelles, M. 2017. Technological Options for Biogenic Waste and Residues - Overview of Current Solutions and Developments. In: Ghosh, S. K.: 7th International Conference on Solid Waste Management. (Ed.): Globals Waste Management: Proceedings of the 7th IconSWM 2017, 1029 - 1044.

Schüch, A.; Nelles, M.; Nassour, A., 2017. Nachhaltige energetische Nutzung biogener Ressourcen durch industrielle Synergien. In: Nelles, M. (Hrsg.) 11. Rostocker Bioenergieforum: Am 22. und 23. Juni 2017 an der Universität Rostock: Tagungsband. Rostock: Professur Abfall- und Stoffstromwirtschaft Agrar- und Umweltwissenschaftliche Fakultät Universität. ISBN: 978-3-86009-455-6. S. 363-371.

Sprafke, J.; Engler, N.; Nelles, M.; Schüch, A. Bioabfallvergärung - Prozessoptimierung durch Substrat-management. In: Nelles, M.: 13. Rostocker Bioenergieforum. Rostock, 2018. ISBN 978-3-86009487-7, 135 - 142.

StatA MV (2017): Statistisches Jahrbuch 2017, StatA MV, 19 Energie

StatA MV (2018): Statistisches Jahrbuch 2018 (Kennziffer: Z011 2018 00), ISBN-13 978-3-9316-54-34-4.

StatA MV (2019): Statistisches Jahrbuch 2019, StatA MV, 19 Energie

Szarka, N.; Scholwin, F.; Trommler, M.; Jacobi, H. F.; Eichhorn, M.; Ortwein, A.; Thrän, D., 2013. A novel role for bioenergy: A flexible, demand-oriented power supply. Energy 61, 18-26, https://doi. org/10.1016/j.energy.2012.12.053

Orth, M.; Schüch, A. (2018): Die Rolle der Bioenergie bei der Sektorenkopplung in MV. In: Nelles, M.: 12. Rostocker Bioenergieforum. Rostock, 2018. ISBN 978-3-86009-473-0, 35 - 47.

Park, A.; Kim, Y. M.; Kim, J. F.; Lee, P. S.; Cho, Y. H.; Park, H. S., 2017. Biogas upgrading using membrane contactor process. Pressure-cascaded stripping configuration. Separation and Purification Technology 183, 358-365. DOI: 10.1016/j.seppur.2017.03.006

Piotrowski, S.; Carus, M.; Essel, R. (2015): Global bioeconomy in the conflict between biomass supply and demand. Hürth (7). In nova paper on bio-based economy.

Veolia, 2019. Teilstromvergärungsanlage Rostock, https://www.veolia.de/teilstromvergaerungsanlage-rostock, last website visit on 23.05.2019. 